The Information Society

An International Journal

ISSN: 0197-2243 (Print) 1087-6537 (Online) Journal homepage: http://www.tandfonline.com/loi/utis20

\title{
Embodied engagements with online pornography
}

\section{Patrick Keilty}

To cite this article: Patrick Keilty (2016) Embodied engagements with online pornography, The Information Society, 32:1, 64-73, DOI: 10.1080/01972243.2015.1107162

To link to this article: http://dx.doi.org/10.1080/01972243.2015.1107162

\section{曲 Published online: 22 Dec 2015.}

Submit your article to this journal $\pi$

Џll Article views: 224

Q View related articles $\square$

View Crossmark data ¿

7 Citing articles: 1 View citing articles 5 


\title{
Embodied engagements with online pornography
}

\author{
Patrick Keilty \\ Faculty of Information, University of Toronto, Toronto, Canada
}

\begin{abstract}
Even though sexual arousal is a central feature in browsing online pornography, embodiment has largely gone unexamined in much of the research on pornography in information studies and human-computer interaction. Through existential phenomenology, which emphasizes a synthesis of cognitive reflection and embodied experience, this article examines how our embodied engagements with the technological apparatus of the computer help reconstitute the way we feel time, objects of desire, and pleasure in the process of browsing online pornography.
\end{abstract}

\section{ARTICLE HISTORY}

Received 24 February 2013

Accepted 9 May 2015

\section{KEYWORDS}

Embodiment; humancomputer interaction; online pornography; sexuality
Sexual arousal is central to the experience of browsing online pornography. Yet, information studies and human-computer interaction researchers have largely overlooked it. Through a synthesis of cognitive reflection and embodied experience that existential phenomenology advances, this article examines how our embodied engagements with the computer helps reconstitute the way we feel time, objects of desire, and pleasure while browsing online pornography. In the process, this essay demonstrates a new mode of description that seeks a synthesis between cognitive reflection and embodied experience in examining our engagements with online pornography.

Perhaps carnal responses to pornography have been considered too crude to invite much investigation. Or perhaps studying the sensuous and affective dimensions of pornography is affiliated with imprecise humanistic criticism in favor of more "rigorous" and "objective" (usually quantitative) modes of description. The neglect to examine carnal responses in pornography may reflect an assumption that our engagement with information systems is fundamentally cognitive. The cognitive turn within information studies marked greater insights into our engagements with information systems. The cognitive nature of our engagements with these systems is famously given in a formula by Brookes (1975) and articulated later with broader philosophical foundation (Brookes 1980). The applications of these ideas feature prominently in Belkin (1980) and others (Belkin, Oddy, and Brooks 1982), who explicitly assess the theory and works of Brookes (Belkin 1990). Later researchers have built upon this work, sometimes explicitly, sometimes implicitly. Dervin's (1983) sense-making model and Bates's (1989) browsing model both begin with the cognitive theory that changes occur between a negotiation of our mental construct of the world and new information received from our engagements with information systems. Dervin's sense-making model concludes that there is a gap between faculty perception and cognition that must ultimately must be reconciled in some way, though generally cognitive.

More recently, Hartel (2007) has overturned some of the basic assumptions of the cognitive theory in finding that our engagements with information systems persist beyond the point of "information need," and that we often engage with information systems for pleasure. In doing so, Hartel implies an affective engagement with information systems. Kari and Hartel (2007) call for a focus within information studies on the pleasurable and profound. A number of other scholars have previously focused on affect, yet with an assumption that it impedes our engagements with information systems, a negative affect instead of a pleasurable one. Most prominently, James and Nahl (1996) find that affect plays a serious role in our engagements with information systems, yet their quantitative descriptions identify affect as disruptive. They offer methods for "coping assistance" to "mitigate" affect by "achieving focus" in order to return to an "ongoing cognitive operation." Nahl and Bilal (2007) again mostly focus on negative affects, such as anxiety, and as a carry-on component of a more traditionally conceived cognitive task.

S. D. Neill (1990), too, gives ample attention to affect in his study of the way embodiment, as a form of 
cognition, is important in learning physical skills, the use of feeling to prefigure thought, and the development of synthetic knowledge, moments of intuition or insight, the way we develop general senses of complex senses or people, or as general structural foundation for conceptual knowledge. Similarly, Olsson (2010), in studying theater professionals, argues that embodiment is a central aspect in understanding subjectivity's relationship to information. Both Neill and Olsson indicate that the idea of embodiment is insufficiently incorporated into our theories of information. Yet they also both largely understand the body as it relates to specifically cognitive phenomena.

Pornography is one type of document that is full of affective and embodied engagements. One might easily have studied funk music or horror films as other documentary genres with strong affective appeal. Yet pornography is so profoundly affective, especially in online environments that have transfixed information studies for several decades, that it may turn out that we have seriously underestimated how common embodiment is as a dimension of our engagements with information systems. In addition, pornography contributes to Neill's and Olsson's understanding of embodiment as a form of cognition while making a difference to the cognitive theory that has long dominated the field by showing that embodiment and cognition operate concomitantly.

Indeed, the perception of pornography cannot be reduced to a question of cognition alone, just as sensation cannot be equated with "the reflective consciousness of sensation," as Steven Shaviro $(1993,26)$ points out. In other words, perception cannot reduce only to the senses, just as sensation does not wholly constitute conscious knowledge. Shaviro continues:

The Hegelian and structuralist equation suppresses the body. It ignores or abstracts away from the primordial forms of raw sensation: affect, excitation, stimulation, and repression, pleasure and pain, shock and habit. It posits instead disincarnate eye and ear whose data are immediately objectified in the form of self-conscious awareness or positive knowledge. (Shaviro 1993, 26-27)

Therefore, the perception of pornography makes meaning before it makes conscious, reflective thought.

The catch-all phrase "sexual information" is a good example of the way in which information scholars have attempted (somewhat defensively, I think) to put the ambiguous, sensuous, embodied realm of pornography into objective, detached, and ambiguous terms (Spink, Koricich, Jansen, and Cole 2004; Spink, Ozmutlu, and Lorence 2004). ${ }^{1}$ Yet viewers of pornography do not wish to be exempt from sensual being in searching pornography online. The pornographic experience is meaningful to viewers precisely because of their bodies. According to Vivian Sobchack,
As "lived bodies" (to use a phenomenological term that insists on "the" objective body as always also lived subjectively as "my" body, diacritically invested and active in making sense and meaning in and of the world), our vision is always already "fleshed out." Even at the movies our vision and hearing are informed and given meaning by our other modes of sensory access to the world: our capacity not only to see and to hear but also to touch, to smell, to taste, and always to proprioceptively feel our weight, dimension, gravity, and movement in the world. (Sobchack 2004, 60)

Thus, the body is not only immersed in making meaning but also physical sense. Pornographic images provoke the "carnal thoughts that ground and inform conscious analysis" (Sobchack 2004, 60). To the extent that it attempts to arouse sexual feelings, pornography functions in and through a direct visceral appear to the body.

Perception owes as much to embodied existence as it does to conscious thought. Cognitive-based models within information studies commonly describe the way we perceive our world and others through our engagements with information as "sense-making," most notably Brenda Dervin (1992; Dervin and Foreman-Wernet 2003). While Dervin cites phenomenological theorists, her sense-making model has little to say about embodied ways of knowing. By considering the senses, following Maurice Merleau-Ponty (1964a; 1964b; 1970; 1988; 2005; 2008), I am offering a different account of perception. To suggest that perception is either embodied or conscious is to reproduce Cartesian dualism's mind/ body split. One should not make the mistake, however, of thinking that carnality and consciousness are equally valued in every perceptive situation; they are not fully disclosed to each other, and at times one might preoccupy us more than the other.

Perception is neither purely conscious nor corporal; rather, it is mediated through both consciousness and corporality and therefore always indirect and incomplete. We cannot accomplish a holistic analysis of our experience of browsing online pornography through a methodology that attends only to conscious experience at the expense of embodied experience. Such is embodiment's centrality to this particular kind of browsing activity. An analysis of our engagements with and activity around online pornography must synthesize cognitive reflection and embodied experience.

\section{New modes of description}

Existential phenomenology seeks such a synthesis. Because I am concerned with the decidedly material nature of human existence, specifically our embodied encounters with and activity around online 
pornography, I have adopted a method of critical practice guided by existential phenomenology. Ihde $(1990,1)$ characterizes this method as "a philosophical style that emphasizes a certain interpretation of human experience, and that, in particular, concerns perception and bodily activity." Merleau-Ponty (1988), the philosopher whose work on embodiment transformed transcendental phenomenology into existential phenomenology, explains that the purpose of this method is "to describe the animation of the human body, not in terms of the descent into it of pure consciousness or reflection, but as a metamorphosis of life and the body, as the "body of the spirit" (196). Finally, Sobchack $(2004,5)$, in her study of film and embodiment, describes existential phenomenology as "philosophically grounded on the carnal, fleshy, objective foundations of subjective consciousness as it engages and is transformed by and in the world." Combining an analysis of bodily activity with the reflective process of writing and scholarship, existential phenomenology synthesizes both cognitive reflection and embodied experience.

Sobchack's emphasis on our bodies' engagement and transformation by and in the world reminds us that embodied experience is always shaped by the context of history and culture. Embodiment does not take place apart from an historical and cultural existence. As such, embodiment cannot be reduced to fixed essences; instead, embodied experiences are always open to other interpretations. Existential phenomenology is, therefore, a subjective method that will help improve our understanding of the way our bodies, in addition to conscious, reflective thought, engage in certain browsing processes.

Examining our embodied encounters with the technical apparatus of the computer does not adhere easily to behaviorist and scientific modes of description. Computer technologies and their attendant networks of communication (including televisual, audiovisual, cinematic, and photographic) are never merely used, never merely instrumental. As I show in the following, they are part of our lives and help constitute our embodied existence in ways that are profoundly personal. It is, therefore, not an exaggeration to say that our encounters with the objective phenomena of computer technologies transform us as embodied subjects and alter our subjectivity.

Subjective analysis, particularly a focus on what it is to live one's body, is at least partly anecdotal to the extent that it relies on lived experience. It is important to remember that embodiment is fundamentally part of what it is to be human (we are bodies; we do not have bodies). That is to say, embodiment, in addition to conscious, reflective thought, helps constitute our subjectivity. The purpose of analyzing the subjective (and sometimes personal) experience is not to universalize a particular experience. Neither should we confuse the process of subjectivity with individualism or particularity. As Braidotti $(2002,7)$ explains, "Subjectivity is a socially mediated process. Consequently, the emergence of new social subjects is always a collective enterprise, external to the self while it also mobilizes the selfs indepth structure." My turn to the subjective second person plural pronoun ("we") reflects the collective enterprise of subjectivity. Furthermore, the intention of my subjective analysis is to open up (rather than close down) our understanding of more general entailments of our engagements with and activity around online pornography and to suggest an intimate and material relationship we have with those engagements and activities.

A turn to the subjective is not merely a self-indulgent analysis of an individual encounter with online pornography. Its aim is to describe and explicate the general and possible structures that inform this particular browsing process and make it potentially resonant for others. Sobchack $(2004,1)$ puts it best in the following passage:

Although in historical and cultural existence particular experiences may be lived idiosyncratically, they are also, and in most cases, lived both generally and conventionally-in the first instance, according to general conditions of embodied existence such as temporality, spatiality, intentionality, reflection, and reflexivity and, in the second instance, according to usually transparent and dominant cultural habits that are not so much determining as they are regulative.

Much of this comes through in my analysis in the following, but I want to emphasize that the value of subjective experience is not necessarily whether I have actually had the experience (indeed, that is besides the point); it is about whether or not "the description is resonant and the experience's structure sufficiently comprehensible to a reader who might possibly inhabit it (even if in a differently inflected or values way)" (Sobchack, 2004, 1). Finally, to the extent that the experience of online pornography is embodied and intimate, subjective logic serves as an antidote to the behaviorist and scientific accounts of our experience of online pornography that do not describe our living that experience.

\section{Duration}

An analysis of our engagements with and activity around online pornography that relies on existential phenomenology should perhaps start with an explanation of how such activity constitutes "browsing" rather than "searching." Scholars predominantly use the latter term to describe activity around online pornography. "Searching" implies a goal-oriented, purposeful activity, whereas "browsing," according to Case (2007, 329), emphasizes 
accidental, incidental, or serendipitous encounters with information. Browsing has a close association with recent studies that concern leisurely and pleasurable information activities. In her study on the information activity of gourmet food cooking, Hartel (2007) shows that browsing can characterize activity in which pleasure derives from the process of the "search" itself. Hartel's gourmet food hobbyists do not necessarily identify in advance an exact recipe they want, nor do they necessarily favor the easiest path to finding it. Instead, the activity reveals a pleasure in serendipitous discovery. Because not just any recipe will do, the hobbyists in Hartel's study derive pleasure from the hard-to-find object. Such activity is not analogous to, say, searching online for the cheapest and most convenient plane tickets-in which pleasure derives from finding a precise object, specified in advance, using the least amount of time and effort.

By showing that we expend significant effort in our pleasurable browsing activities, Hartel and Case undercut the use to which some scholars have put Zipfs (1949) notion of the economy of effort (or the Principle of Least Effort) to explain the way we search engage with information systems. Such an explanation assumes that the effort of browsing or searching is always unpleasant and that displeasure increases with the duration of that effort. Hartel and Case also undercut the assertion made by Choo (2001a; 2001b) that goal-oriented or purposeful searching requires greater effort than browsing.

Hartel's characterization of pleasurable browsing in some ways echoes that of online pornography. Yet our relations to representations of sexual desire and the illusive goal of browsing pornography complicate our understanding of pleasurable browsing in important ways. The process of browsing pornography online exists under the aegis of getting what we want, but in excess of it. Floods of images and an enormous range of selection seem to promise satisfaction. To the extent that browsing online pornography is at all pleasurable, we might assume that it is also enjoyable and satisfying, in Seligman and Csikszentmihalyi's (2000) understanding of pleasurable. In this way, browsing pornography has a discernable, albeit ostensible, goal or objective: sexual satisfaction. The aegis of such a goal in part allows us to rationalize the pleasure of browsing. To imagine the goal is to project into a moment of perfect satisfaction: obtaining the perfect image, one completely adequate to our desire.

However, nothing can compare to an imagined perfect image, not just any image will do, and so the browsing experience continues. Following Lacan (1992; 2007), Salvoj Žižek (1997) has succinctly articulated the impossibility of fulfilling one's desire: "desire's raison d'etre is not to rationalize its goal, to find full satisfaction, but to reproduce itself as desire" (39). Thus, satisfaction is illusive. The nearly perfect image still only provides momentary satisfaction. In some instances, momentarily satisfied or frustrated, we walk away from the computer, only to return to it again at a later point because of the recursive nature of sexual desire. In other instances, even if we know we are unlikely to find a better image, we will continue to browse, forgoing the pleasures of the known for the pleasures of the unknown. We constantly shift to new images, creating a process of browsing in which pleasure derives from the habitual and repetitious delay and deferral of satisfaction. Derrida $(1993,34)$ describes this process of delay and deferral as arrivant, the active form of the French verb arriver, which means to arrive at a goal or fulfill an intention. Arrivant, thus, describes the process of arriving at a goal or objective without ever attaining it. We might also describe this non-teleological phenomenon as the sensation of being in duration.

Indeed, the process of browsing online pornography is one marked by the embodied experience of waiting. While the Internet promises immediate gratification, the interface of online pornography necessitates delays: logging on, finding a site, scrolling up and down/left and right, opening and closing windows, clicking forward/ backward, and pushing the refresh button. Delays also arise from the material limitations of the technological apparatus of the computer, such as the capacity of silicon to conduct electrons at particular speeds, which results in the delay of waiting for a selected image, series of images, or moving image to appear. A high-speed Internet connection may decrease this delay, but, according to Patterson (2004), "Cyberporn constantly pushes the boundaries of bandwidth; as soon as the technology can immediately deliver full-frame images, streaming video comes on offer, with slower load times. Even with a high-speed connection, there is still often delay on the side of the site delivering content" (109). Waiting and looking become habit, thereby "inscribing repetition and delay as pleasures of a different order" (Patterson 2004, 109). At some point, there is a limit to the amount of waiting we will endure before our browsing experience becomes frustrating, but until that threshold, delay intensifies the pleasure of eventual visibility, amassed by the illusoriness of the perfect image.

Part of our frustration and delay may also owe to the labyrinthine design quality of some pornography websites. Websites with this method of design provide an overflow of images and moving images, arranged in a rambling and chaotic fashion, opposed to concepts of ordering and system. Think especially of pop-ups, advertisements, and flash and animated GIFs, not to mention sites with background music. Such a concept of design participates in delivering an excess and overflow. In this way, the design of some pornography websites seems to promise the accessible and visible while delivering the curious and 
obscure. ${ }^{2}$ Pornography websites engage us visually, seductively, and affectively, revealing a corporal relation between display and viewer. Scholars of Enlightenment visual culture have similarly shown a corporal relation between exhibition and viewer in the arrangement of objects on display in the Baroque curiosity cabinet. This is not to say that the arrangement of pornographic images online today can be anchored solely in the referents of the early modern period, or that there is some kind of causal effect of old media on new. Instead, the digital functions as part of a baroque genealogy, which articulated differential relations between embodiment and technics. It places, according to Munster (2006, 5), "body and machine, sensation and concept, nature and artifice in ongoing relations of discordance and concordance with each other."3 The arrangement of pornographic images online and the navigation it entails similarly serve an affective experience. Pornography websites' method of display is an aesthetic contrivance that solicits us sensually, drawing wonder, curiosity, surprise, disgust, irritation, and frustration from the viewer. As with the embodied experience of delay, the arrangement of images on display reveals the ways in which we experience both pleasure and frustration in the process of browsing pornography online. ${ }^{4}$

\section{Sensing sensuality}

One cannot engage with online pornography except through the computer as a kind of "material object or instrument with which the user has to interact" (Patterson, 2004, 107). Several habits are present in the process of searching pornography online: pointing and clicking, pushing the refresh button, scrolling up and down, left and right, opening and closing windows, clicking back, clicking forward, right clicking, moving the mouse to such-and-such a point on a surface, and so on. Each of these represents, following Judith Butler's reading of Pierre Bourdieu, "a tacit form of performativity, a citational chain lived and believed at the level of the body" (Butler 1997, 155). While the computer does not determine the actions of any particular user, it inscribes pre-existing relations by reproducing them onto the body through gesture and repetition. Put another way, users are inclined to adhere to the preexisting relationship between their body and the computer. According to Martin Heidegger (1962), it is not that technology causes behavior but "brings-forth," "occasions," "presences," or "reveals" behavior (6-12). The mechanisms through which one views pornography online insist on certain movements of the body, which become habit through repetition.

Brian Massumi describes these habits as "muscular memory of relationality," created by tactility. "The muscles and ligaments register as conditions of movement," according to Massumi (2002), "what the skin internalizes as qualities" (58). For example, the softness of a cat's fur becomes a lubricant for the movement of a hand. Indeed, "muscle memory" (also known as neuromuscular facilitation) is a common phenomenon. Indeed, bodily habit is an insistent aspect of browsing pornography online as well. I put little cognition in right clicking and selecting a menu option. My muscles know precisely how far down to drag the mouse to the particular location of my desired menu option without my having to reflect on the action. Typing functions much the same way. Eventually, the arrangement of the keyboard is so instinctually embodied into our computer experience that we hardly reflect on the individual keys as our fingers press them.

In this way, the computer is a sexual technology. The computer arranges the viewer's body when browsing pornography online in several ways-for example, the location of feet placed beneath the desk or above the desk, crossed legs, straight legs, curling toes, relaxing toes, sitting forward, sitting back, sitting up, slouching, contracting muscles, relaxing muscles-each accompanied by a whole range of sensations-frustration, pleasure, anxiety, disgust, exhaustion, shame, excitement, panic, and so on. One's body is limited to a number of physical arrangements, confined by the physical presence and specificity of the computer to a particular place, bound to the instrument of pleasure like a restraint. Understanding these insistent mechanisms offers us a denser understanding of this particular activity.

Our embodied experience of browsing pornography online is an experience of seeing, hearing, touching, and moving in which our sense of the literal and the figural vacillate, sometimes discontinuously, but usually configuring to make sense and meaning together. This is because, according to Sobchack (2004), "we are incorporated systemically as embodied and conscious subjects who both 'have' and 'make' sense simultaneously" (75, emphasis in original). To have and to make sense is an undifferentiated experience that grounds and conjoins body and language, feeling and knowledge. Alphonso Lingis, too, has emphasized the conjunction of the lived body and representation: "My body as the inner sphere where representations are perceptible ... and my body as an image seen by rebound from the world, are inscribed the one in [the] other... The density of the body is that of 'pre-things,' not yet differentiated into reality and illusion ... [The] body is a precinct of signifiers" (Lingis 1993, 162). For Lingis, then, the literal and the figural inform each other even as they inform us. We are both embodied and conscious in that we both have and make sense.

The process of seeking pornography online especially highlights and privileges the conjoined relation between the lived body and representation because it uses lived modes of perceptual and sensory experience to represent 
bodies that are also participating in lived modes of perception. Granted, porn viewers cannot fully caress the smooth shoulders of the man on the computer screen; the precise smell and warmth of the body on screen remain vague. Nevertheless, viewers have a partially fulfilled sensory experience of these things that makes them both conscious and meaningful. This experience is not reducible only to one's senses or only to cognitive reflection.

Needless to say, the structure of this fulfillment is quite different in several ways from a context in which the man is literally present. One's lived body sits in readiness in front of the screen as both a sensual and sensemaking potentiality. Focused on the screen, the viewer's "postural schema" takes its shape based on an inclination toward (or uninterested recoil from) what she sees and hears. "If I am engaged by what I see," writes Sochchack, "my intentionality streams toward the world onscreen, marking itself not merely in my conscious attention but always also in my bodily tension" $(2004,76)$. This tension reveals itself sometimes subtly, sometimes blatantly, but always as an arrangement of one's material being: the body contorts, retracts, straightens, bows, cocks, reclines, gravitates, recoils, slumps, and so on. While online browsing cannot fulfill certain sensory experiences (touch, smell, taste), when physically aroused, Sobchack writes, the "body's intentional trajectory, seeking a sensible object to fulfill this sensual solicitation, will reverse its direction to locate its partially frustrated sensual grasp on something more literally accessible. That more literally accessible sensual object is my own subjectively felt lived body" (2004, 76, emphasis in original).

Although Sobchack is discussing her experience watching a film, embodied experience of browsing pornography online shares cinematic elements. Indeed, we cannot assume that electronic presence completely breaks from the procedures of cinema and photography. Digital representation participates in a broad network of communication that includes the cinematic and photographic. In an electronic cinematic presence, one is "in rebound" (recalling Lingis) from the screen, turning reflexively (un-reflectively) "toward my own carnal, sensual, and sensible being to touch myself touching, smell myself smelling, taste myself tasting, and, in sum, sense my own sensuality" (Sobchack 2004, 77).

Merleau-Ponty has described this phenomenon as our lived body's capacity to sense itself:

There is a relation of my body to itself which makes it the vinculum of the self and things. When my right hand touches my left, I am aware of it as a "physical thing." But at the same moment, if I wish, an extraordinary event takes place: here is my left hand as well starting to perceive my right ... Thus I touch myself touching; my body accomplishes "a sort of reflection."
In it, through it, there is not just the unidirectional relationship of the one who perceives to what he perceives. The relationship is reversed, the touched hand becomes the touching hand, and I am obliged to say that the sense of touch is here diffused into the body-that body is a "perceiving thing," a "subject-object." (Merleau-Ponty 1964, 166)

This description of the lived body's capacity to sense itself, when considered in the context of browsing pornography online, coupled with Lingis's description of sensing one's own sensuality, sounds remarkably similar to masturbation. Effectively a form of "self-touching," it can also be described as "autoerotic," "spontaneous eroticism," or "self-eroticism." Viewers, thus, take pleasure from both seeing and feeling in the process of browsing pornography online. The touching in pornography (the smooch of a kiss, the touch of a shoulder) becomes actualized as the touch of oneself. The pleasure represented by the image is physically felt by the viewer as she touches herself.

This form of self-touching is consciously otherdirected, and as such, some might argue, it maintains the subject/object distinction because it is different from forms of self-touching in which one's body and one's consciousness is self-directed. Narcissism aside, however, one's consciousness is never entirely self-directed and it would seem that masturbation demands special focus on an external, if also imaginary, figure of desire. It is precisely because one's consciousness is not directed toward one's own body but toward the figure of desire onscreen that the subject/object distinction remains interlaced rather than distinct. The diffusion of consciousness is matched by a dispersion of embodiment. The viewer is "caught up without a thought (because [my] thoughts are 'elsewhere') in this vascillating and reversible structure that both differentiates and connects the sense of my literal body to the sense of the figurative bodies and objects I see on the screen" (Sobchack 2004, 78, emphasis in original).

To the extent that viewers are provoked by figural objects that are elsewhere, we are not focused on the particularities of our literal bodies either. My perception of the figure on screen and my sense of self are, therefore, vague and diffuse, even as the interaction heightens and intensifies my sensorium. At the moment one's lived body, in rebound, senses itself in the online pornographic experience, the particular objects that sensually provoke the viewer are perceived in vague and diffuse ways. One's body is the site where the sensual event of representation occurs, where the sexual solicitation by the figure onscreen and our own self-touching become diffused into our bodies. Thus, the literal body and the figural bodies onscreen are both differentiated and connected. 
Furthermore, a form of autoeroticism in which one's body and one's consciousness are self-directed requires such cognitive reflection and attention toward oneselfwhat Sobchack calls a kind of double reflexivity-that it can and often does undo carnal pleasure. Sobchack points out that it is nearly impossible to tickle oneself, for self-consciousness of our laughing results in it becoming forced. The process of browsing pornography online collapses the distinction between object and subject insofar as browsing for sexual representation participates in perceptual "rebound." At that moment, the search reflects sexual desire itself as necessarily otherdirected and requires an object other than oneself "so as to avoid a reflexivity that is so doubled as to cause conscious reflection on sexual desire itself" (Sobchack 2004, 78). One might even claim, then, that seeking sexual objects online fails to be pleasurable at the moment it becomes consciously reflective.

In these moments, one does not think about one's own body, and one is not, therefore, thrust outside of the onscreen image. Instead, viewers are immersed in the image; they feel their bodies as only one side of "an irreducible and dynamic relational structure of reversibility and reciprocity" that has as its other side the figural body onscreen (Sobchack 2004, 79). It is a process of reflexive and reflective exchange that allows viewers literally to feel the warmth, moisture, and smoothness of a body.

This relation can be broken, not only by conscious reflectivity by also by reflexive feelings of shame, disgust, or the panic of being discovered by someone outside the scene intruding upon the moment (entering the picture, if you will). The intensity of these feelings attest to the body's relation to the figure on the screen, its sense of investment in what it sees, hears, tastes, touches, and smells. Consider, for example, when we cover our eyes or ears in a slasher film, literally sickened at the sight of blood, terrified by the psychopathic murderer, and frightened, frustrated, or anxious at the victim's impending doom. These all attest to the conjoined relationship between the figural body onscreen and our literal body in the movie theatre-an affective experience that is carnally and consciously meaningful. Similarly, browsing pornography has a carnal and conscious relation to pornographic images, conjoined by the always reflexive and reflective exchange of sensation that defines the autoerotic goals of this particular browsing process.

\section{Conclusion}

In this essay, I have demonstrated a new mode of description that seeks a synthesis between cognitive reflection and embodied experience in examining our engagements with online pornography. In the process, I have shown that computer technologies and their attendant network of communication (including televisual, audiovisual, cinematic, and photographic) are part of our lives and help constitute our embodied existence in ways that are socially pervasive and profoundly personal. Technology is never merely used, never merely instrumental. It is, therefore, not an exaggeration to say that encounters with the objective phenomena of computer technologies transform us as embodied subjects and alter our subjectivity. That desire is recursive, involves delay and deferral, and that its goal is illusive at least partly explains the time and effort we put into browsing representations of it. Our embodied engagements with the technological apparatus of the computer helps reconstitute the way we feel time, objects of desire, and pleasure in the process of browsing online pornography. Focusing on the habits and duration of online pornography, this essay reveals a technical mediation, in which subjects and objects mediate and co-constitute each other: We are different in front of a computer; the computer is different when we engage with it. The computer is another object because it has entered into a relationship with you. You are another subject because you're engaging the computer (Latour 1994). Hence, this essay is not only a shift away from the cognitive turn in information studies; it also emphasizes the ways in which examining technical mediation can produce new modes of description that reveal a different understanding of our relationship to objects.

While much of this essay has focused on what difference pornography makes to information studies, it is important to highlight what difference information studies makes to pornography studies. Information systems are omnipresent in contemporary society and, indeed, a defining feature of our contemporary world. Information scholars have long focused on the mediation of documents and objects by information systems. Indeed, information systems increasingly mediate our engagement with pornography. Yet few scholars of pornography consider data clustering, algorithms, metadata, different modes or browsing, or other information elements in the way pornography is arranged and displayed, or how these elements make a difference to our engagements with representations of sex. Instead, pornography scholars tend to view information systems as instruments of rationality, rather than narrative constructs or sociocultural systems. However, information scholars, following Suzanne Briet, have long understood that a catalog or index not only points to the object but also reflects the social network in which that object appears (Day 2006).

Attenuating pornography scholars to the way in which information systems mediate pornography might help us to understand how information systems change our engagements with pornography-how, for example, a different display can create a different narrative 
construct, what role metadata plays in creating fetishistic networks, or how algorithms can account for browsing patterns (Keilty and Leazer 2014). Furthermore, following Bates (1989), information scholars have long understood that different objects are sought differently. This is to say, not only do information systems mediate different objects differently, but we also have a different engagement with those systems depending on what objects we seek. Indeed, information systems radically transform objects and objects radically transform our engagement with information systems. The relation is meditational. We engage with the information system differently depending on the object it mediates, and the information system transforms the object it mediates. In this way, information systems partly construct our engagements with pornography. Particularly in an online context, pornography and information systems produce meaning together. Therefore, meaning cannot be only located in representational qualities but in the mediation of that representation. We must understand the dynamic interaction between the two.

Finally, due to the limitations of space, this essay has said nothing about the role of embodiment in sexual sociability online. Indeed, browsing online pornography is a social experience. "There are literally hundreds of thousands of sites that cater to every masturbatory fantasy imaginable," writes Laqueur (2003, 419), "but what is really new is the proliferation of virtual communities of onanaists, an alternative universe of sociability that is created through the public revelation of the not-so-vice." Laqueur suggests that these online communities of masturbators constitute a change in the history of masturbation. Once a solitary sexual pleasure, marked by privacy, loneliness, self-absorption, guilt, and shame, masturbation has come to be an increasingly public, social, and communal experience online. Some of the evidence for this may come from the incorporation of social networking design elements into pornography websites. Other evidence comes from the way in which we browse, organize, and retrieve online pornography through folksonomic forms of classification (tags) that allow for effective retrieval systems (Keilty 2012b). Algorithms mediate some of these relations, recommending images or moving images that others found interesting, similar to Amazon.com ("customers who bought this item also bought"). An examination of the social aspects of browsing online pornography might include a discussion of mobile technologies. Not all users are bound to the computer. Rapidly changing technology means that many users are able to access online pornography, often with greater mobility-from televisions, cellphones, and laptop computers-thereby dramatically changing physical habits necessary to access pornographic material. We must engage with the material specificity of mobile technologies, each of which contains its own insistent mechanisms that engage the body.

\section{Notes}

1. Spink et al. rely on evolutionary psychology to understand why people search pornography online. In doing so, Spink et al. rhetorically arrogate the authority of evolutionary science in order to lend a sense of objectivity and detachment to a potentially prurient discussion. As I have discussed at length elsewhere (Keilty 2012a), Spink et al. evacuate sexual reproduction of its cultural context and exclude the sexual desires of nonreproductive and queer bodies. By making sexual reproduction the paradigm of sexual desire, Spink et al. render non-heteroreproductive bodies derivative of heterosexuality. As such, they privilege heteronormative romantic love and kinship.

2. Even if pornography websites contain classification schemas to make information retrieval effective through keyword searches, the choice of categories of fetishes is regulatory productive. The classification functions to guide, if not overtly discipline, our subject positions and desires by creating an environment in which subjects and desires are produced as essential standards. Folksonomic classifications, such as tags, reflect a complicated relationship with the dominant culture. While the bounds of power are not always top-down, folksonomic classification is not free of discipline. On this point, see especially Keilty (2012b). While we might role-play within these classifications, the exploration is constrained by a logic of recognizable cues, yet made obscure by the lack of transparency of language, in which a keyword returns false hits, further attributing to the labyrinthine design quality of certain pornography websites.

3. Numerous scholars have articulated that digital visual culture participates in a baroque genealogy, notably Munster (2006) and Murray (2008).

4. Sigmund Freud famously described the association of frustration and pleasure in his theory of cathexis. According to Freud (1990), the psychic energy found in the id, which is responsible for satisfying basic desires, invests itself in an object, idea, or person in order to satisfy that desire, as in the case of sexual imagery. Freud represents frustration in libidinal desires as a blockage of psychic energy passing through the id. If sexual representation is a form of object-cathexis, then viewers browsing pornography experience libidinal frustration in the delay and deferral of sexual satisfaction.

5. "Auto-eroticism," according to the Oxford English Dictionary (2009), is synonymous with "spontaneous eroticism" and "self-eroticism

\section{References}

Bates, M. J. 1989. The design of browsing and berrypicking techniques for online search interface. Online Information Review 13 (5):407-24.

Belkin, N. J. 1980. Anomalous states of knowledge as the basis for information retrieval. Canadian Journal of Information Science 5:133-43. 
Belkin, N. J., R. Oddy, and H. Brooks. 1982. ASK for information retrieval. Journal of Documentation 38:61-71 (part 1) and 145-164 (part 2).

Belkin, N. J. 1990. The cognitive viewpoint in information science. Journal of Information Science 16 (1):11-15.

Braidotti, R. 2002. Metamorphoses: Towards a materialist theory of becoming. Malden, MA: Blackwell/Polity Press.

Brookes, B. C. 1975. The fundamental equation of information science. In Problems of information science, ed. A. I. Chernyi (FID 530), 115-30. Moscow, USSR: All-Union Institute for Scientific and Technical Information.

Brookes, B. C. 1980. The foundations of information science Part I. Philosophical aspects. Journal of Information Science 2 (3-4):125-33.

Butler, J. 1997. Excitable speech: A politics of the performative. New York, NY: Routledge.

Case, D. 2007. Looking for information: A survey of research in information seeking, needs, and behavior. New York, NY: Elsevier.

Choo, C. W. 2001a. Environmental scanning as information seeking and organizational learning. Information Research 17 (1). http://informationr.net/ir/7-1/paper112.html (accessed August 22, 2011).

Choo, C. W. 2001b. Information management for intelligent organization: The art of scanning the environment. Medford, NJ: Information Today.

Day, R. E. 2006. 'A necessity of our time': Documentation as 'cultural technique.' In What is documentation? English translation of the classic French text (by S. Briet), ed. R. E. Day and L. Martinet with H. G. B. Anghelescu (editors and translators), 47-63. Lanham, MD: Scarecrow.

Derrida, J. 1993. Aporias, trans. T. Dutoit. Stanford, CA: Stanford University Press

Dervin, B. 1983. An overview of sense-making research: Concepts, methods, and results to date. Paper presented at the International Communication Association Annual Conference, Dallas, TX, May. http://faculty.washington.edu/ wpratt/MEBI598/Methods/An\%20Overview\%20of\%20SenseMaking\%20Research\%201983a.htm (accessed October 29, 2014).

Dervin, B. 1992. From the mind's eye of the user: The sensemaking qualitative-quantitative methodology. In Qualitative research in information management, ed. J. Glazier, and R. Powell, 61-84. Englewood, CO: Libraries Unlimited.

Dervin, B., and L. Foreman-Wernet, eds. 2003. Sense-making methodology reader: Select writings of Brenda Dervin. Creskill, NJ: Hampton Press.

Freud, S. 1990. The ego and the id. New York, NY: W. W. Norton.

Hartel, J. 2007. Information activities, resources, and spaces in the hobby of gourmet cooking. Doctoral dissertation, University of California, Los Angeles, CA.

Heidegger, M. 1962. The question concerning technology and other essays, trans. W. Lovitt. New York, NY: Harper Perennial.

Ihde, D. 1990. Technology and the life world: From garden to earth. Bloomington, IN: Indiana University Press.

James, L., and D. Nahl. 1996. Achieving focus, engagement, and acceptance: Three phases of adapting to Internet use. Electronic Journal of Virtual Culture 4 (1). http://www2.hawaii.edu/ $\sim$ nahl/articles/ejvc.html (accessed October 2, 2015).
Kari, J., and J. Hartel. 2007. Information and higher things in life: Addressing the pleasurable and the profound in information science. Journal of the American Society for Information Science \& Technology 58 (8):1131-47.

Keilty, P. 2012a. Embodiment and desire in browsing online pornography. In Proceedings of the iConference 2012, 4147. New York, NY: ACM.

Keilty, P. 2012b. Sexual boundaries and subcultural discipline. Knowledge Organization 39 (6):417-31

Keilty, P., and G. Leazer. 2014. What porn says to information studies: The affective value of documents and the body in information behavior. Proceedings of the American Society of Information Science and Technology 51 (1): $1-11$.

Lacan, J. 1992. The seminar of Jacques Lacan, book VII: The ethics of psychoanalysis, trans. D. Porter. New York, NY: W. W. Norton.

Lacan, J. 2007. Ecrits, trans. Bruce Fink. New York, NY: W. W. Norton.

Laqueur, T. 2003. Solitary sex: A cultural history of masturbation. New York, NY: Zone.

Latour, B. 1994. On technical mediation: Philosophy, sociology, genaeology. Common Knowledge 3 (2):29-64.

Lingis, A. 1993. Bodies that touch us. Thesis Eleven 36 (1):15967.

Massumi, B. 2002. Parables for the virtual: Affect, movement, and sensation. Durham, NC: Duke University Press.

Merleau-Ponty, M. 1964a. Signs, trans. R. C. McCleary. Evanston, IL: Northwestern University Press.

Merleau-Ponty, M. 1964b. The primacy of perception, and other essays on phenomenological psychology, the philosophy of art, history and politics. Evanston, IL: Northwestern University Press.

Merleau-Ponty, M. 1970. Themes from the lectures at the College de France, 1952-1960, trans. J. O’Neill. Evanston, IL: Northwestern University Press.

Merleau-Ponty, M. 1988. In praise of philosophy and other essays, trans. J. Wild and J. M. Edie. Evanston, IL: Northwestern University Press.

Merleau-Ponty, M. 2005. Phenomenology of perception, trans. C. Smith. New York, NY: Routledge.

Merleau-Ponty, M. 2008. The world of perception, trans. O. Davis. New York, NY: Routledge.

Munster, A. 2006. Materializing new media: Embodiment and information aesthetics. Hanover, NH: Dartmouth College Press.

Murray, T. 2008. Digital baroque: New media art and cinematic folds. Minneapolis, MN: University of Minnesota Press.

Nahl, D., and D. Bilal. 2007. Information and emotion: The emergent affective paradigm in information behavior research and theory. Medford, N.J: Information Today.

Neill, S. D. 1990. Body English: The dilemma of the physical in the objectification of subjective knowledge structures: The role of the body in thinking. Journal of Documentation 46 (1):1-15.

Olsson, M. R. 2010. All the world's a stage: Making sense of Shakespeare. Proceedings of the American Society for Information Science \& Technology 47 (1):1-10.

Oxford English Dictionary. 2009. Auto-eroticism. http://www. oed.com/view/Entry/278354? redirectedFrom=auto-eroticis m\#eid (accessed June 2, 2014). 
Patterson, Z. 2004. Going on-line: Consuming pornography in the digital era. In Porn studies, ed. L. Williams, 104-23. Durham, NC: Duke University Press.

Seligman, M. E. P., and M. Csikszentmihalyi. 2000. Positive psychology: An introduction. American Psychologist 55 (1):5-14.

Shaviro, S. 1993. The cinematic body. Minneapolis, MN: University of Minnesota Press.

Sobchack, V. 2004. Carnal thoughts: Embodiment and moving image culture. Berkeley, CA: University of California Press.
Spink, A., A. Koricich, B. J. Jansen, and C. Cole. 2004. Sexual information seeking on Web search engines. CyperPsychology \& Behavior 7 (1):65-72.

Spink, A., H. C. Ozmutlu, and D. P. Lorence. 2004. Web searching for sexual information: An exploratory study. Information Processing \& Management 40 (1):113-24.

Zipf, G. K. 1949. Human behavior and the principle of least effort: An introduction to human ecology. Cambridge, MA: Addison-Wesley.

Žižek, S. 1997. The plague of fantasies. New York, NY: Verso. 